\title{
Metabola syndromet: betydelsen av fysisk aktivitet
}

\author{
Mai-Lis Hellénius \\ Centrum för klinisk hjärtkärlforskning och Konung Gustaf V's Forskningsinstitut, Karolinska sjukhuset, \\ SE-I7I 76 Stockholm, Sweden.
}

\begin{abstract}
The prevalence of overweight, central obesity and the metabolic syndrome is increasing in Sweden. Physical inactivity plays an important role in the pathogenesis of the metabolic syndrome. Physical activity increases energy expenditure and will affect body weight and central obesity. Furthermore, physical activity positively affects lipoprotein metabolism, blood pressure, peripheral insulin sensitivity and fibrinolysis. Consequently, physical activity plays an important role in the prevention and treatment of the metabolic syndrome. Daily low-intensity physical activity and aerobic exercise of moderate intensity for 30 min or more at least twice a week is recommended.
\end{abstract}

Keywords: Physical activity, metabolic syndrome.

\section{Övervikt och bukfetma ökar i Sverige}

Många studier har publicerats de senaste åren som visar att övervikt och bukfetma ökar i Sverige $(1,2)$. Parallellt med detta har ett allt större intresse riktas mot det sk metabola syndromet och dess roll i genesen till kardiovaskulära sjukdomar och diabetes typ II. Genesen till det metabola syndromet är komplex och genetiska faktorer och livsstil interagerar på ett komplicerat sätt. Nedsatt insulinkänslighet och påföljande hyperinsulinemi anses vara central i det metabola syndromet. Övervikt och framför allt bukfetma, är vanligt förekommande och viktiga kliniska karakteristika, liksom hypertoni och dyslipidemi i form av höga triglycerider och låga HDL-nivåer samt små täta aterogena LDL-partiklar. Nedsatt fibrinolytisk förmåga, hyperurikemi och mikroalbuminuri är andra komponenter ofta förekommande i det metabola syndromet $(3,4)$. Epidemiologiska studier som publicerats det senaste decenniet har visat att det metabola syndromet ökar risken för insjuknande i kardiovaskulära sjukdomar och diabetes typ II (5).

\section{Det metabola syndromet är vanligt förekommande hos fysiskt inaktiva män och kvinnor}

I en nystartad populationsbaserad kohort-undersökning av 60-åriga män och kvinnor i Stockholms län (2039 män och 2193 kvinnor, 78\% deltagande) var förekomsten av det metabola syndromet hög och återfanns hos 30 respektive $15 \%$ av männen och kvinnorna (6). Det metabola syndromet ansågs föreligga när minst tre av följande kriterier uppfylldes; midja-stuss kvot $\geq 0.95$ respektive $\geq 0.85$, HDLkolesterol $<1.0$ respektive $<1.1 \mathrm{mmol}^{-1}$, f-insulin $\geq 13.5$ respektive $\geq 11.7 \mathrm{mU}^{1^{-1}} \quad$ (75:e percentilen) för män och kvinnor, f-glukos $\geq 6.1$ mmoll ${ }^{-1}$, s-triglycerider $\geq 1.7 \mathrm{mmoll}^{-1}$, blodtryck systoliskt $\geq 140$ och diastoliskt $\geq 90 \mathrm{mmHg}$.

Deltagarna skattade fysisk aktivitet pa fritiden det senaste året och indelades i fyra olika grupper: (1) fysiskt inaktiva; (2) lätt aktivitet; (3) måttlig aktivitet; (4) regelbunden motion (minst $60 \%$ av maximal kapacitet regelbundet $2-3$ ggr i veckan). Elva procent av männen och $12 \%$ av kvinnorna klassades som fysiskt inaktiva (gr 1) och $9 \%$ respektive $6 \%$ som regelbundna motionärer ( $\mathrm{gr} 4$ ). Merparten av 60åringarna (55\% av männen och $61 \%$ av kvinnorna) uppgav lätt fysisk aktivitet (gr 2). De fysiskt mest aktiva männen och kvinnorna hade generellt en gynnsammare riskfaktorprofil med signifikant lägre vikt, mindre bukfetma, lägre blodtryck, högre HDLkolesterol, lägre LDL/HDL kvot, lägre triglycerider, lägre insulinnivåer och lägre fibrinogennivåer. De rapporterade också en högre grad av välbefinnande. Ett dos-respons samband mellan grad av fysisk aktivitet och olika riskfaktorer sågs. Det metabola syndromet förelåg hos $41 \%$ av de fysiskt inaktiva 
männen jämfört med $16 \%$ hos de fysiskt mest aktiva och motsvarande siffror hos kvinnorna var $26 \%$ respektive $12 \%$ (7). Dessa fynd från en tvärsnittsstudie stämmer väl överens med resultaten frân en nyligen publicerad prospektiv studie på 1860 svenska 50-åriga män som återundersöktes 20 år senare. Vid baslinjeundersöknigen sågs liknande samband mellan fysisk aktivitet och metabola variabler. De som under uppföljningstiden rapporterade ökad fysisk aktivitet på fritiden uppvisade förbättrad glukos-insulin homeostas samt ett förbättrat lipidstatus (8).

\section{Metabola rubbningar gar att behandla med ökad fysisk aktivitet}

Många interventionsstudier har visat att metabola rubbningar förekommande i det metabola syndromet går att behandla med ökad fysisk aktivitet (9-12). I en svensk kontrollerad randomiserad studie bland medelålders män med förhöjda kardiovaskulära riskfaktorer gavs råd om motion av läkare vid ett tillfälle. Motionsdosen ökade från i snitt 5 till 10 motionstillfällen i månaden på fritiden. Efter sex månader sågs en signifikant reduktion av vikt, bukfetma, blodtryck och insulinnivaer i fasta samt under belastning $(11,12)$. Mekanismerna bakom motionens preventiva effekter är många och innefattar bl.a. positiva effekter pa lipoproteiner. Genom att lipoproteinlipas, ett nyckelenzym i lipoprotein metabolismen, aktiveras kommer triglyceridnivåerna att sjunka och HDL-nivåerna att stiga. Studier har även visat en minskande oxideringsbenägenhet hos LDL partiklarna. Fysisk aktivitet har en måttlig blodtryckssänkande effekt hos såväl normotoniker som hypertoniker. Den perifera insulinkänsligheten ökar och glukostoleransen förbättras. Vikt och bukfetma reduceras vid ökad fysisk aktivitet och trombogenesen påverkas i positiv riktning. De facto att verkningsmekanismen är multifaktoriell gör fysisk aktivitet till ett effektivt sätt att förebygga och behandla det metabola syndromet (9) (Fig. 1).

\section{Goda bevis för att diabetes typ II gar att förebygga med förbättrade mat och motionsvanor}

Flera nyligen publicerade kontrollerade randomiserade studier har även visat att förbättrade mat och motionsvanor effektivt kan förhindra insjuknande i diabetes typ II hos högriskindivider (1315). Nyligen visade finska forskare att förbättrade mat- och motionsvanor hos överviktiga medelålders män och kvinnor (n 522, 172 män och 350 kvinnor) med nedsatt glukostolerans kunde minska risken att insjukna i diabetes typ II med $58 \%$ (14). Exakt samma riskreduktion sågs efter kost och motionsintervention $i$ en snarlik men betydligt större studie i USA (15). Det är dock svårt att utröna hur stor del av riskreduktionen $\mathrm{i}$ dessa två omnämnda studier som kan tillskrivas den ökade fysiska aktiviteten.

\section{Motionsrad för att förebygga och behandla det metabola syndromet}

Motion för att förebygga och behandla det metabola syndromet bör vara av typen konditionsträning (promenader, jogging, simning, cykling etc), men även styrketräning kan ha viss effekt (16-18). Intensiteten bör vara måttlig (ca $60 \%$ av den maximala kapaciteten) och motionen bör helst vara regelbunden, gärna dagligen, eftersom vissa av effekterna är kortvariga. Motionstillfällena bör gärna vara 30 min eller mer, men även upprepade kortare episoder kan ha god effekt. Den energiförbrukande effekten av daglig låggradig fysisk aktivitet ska ej underskattas. I en amerikansk undersökning där energiförbrukningen noggrant mättes hos vuxna män ock kvinnor i olika dagliga aktiviteter visades att energiförbrukningen vid en promenad (4.8 km per timme) var $200 \%$ högre än vid vila, exvis liggandes på en soffa eller sittandes stilla i en stol (20 kJ min ${ }^{-1}$ jämfört med $5 \mathrm{~kJ}$ min $^{-1}$ ) (19).

\section{Framgangsrik motionsradgivning i praktiken}

Aktuell beteendevetenskaplig forskning visar att ett patientcentrerat förhållningssätt är det mest framgångrika. Motionsråden bör bygga på den vetenskapliga dokumentation som finns idag men

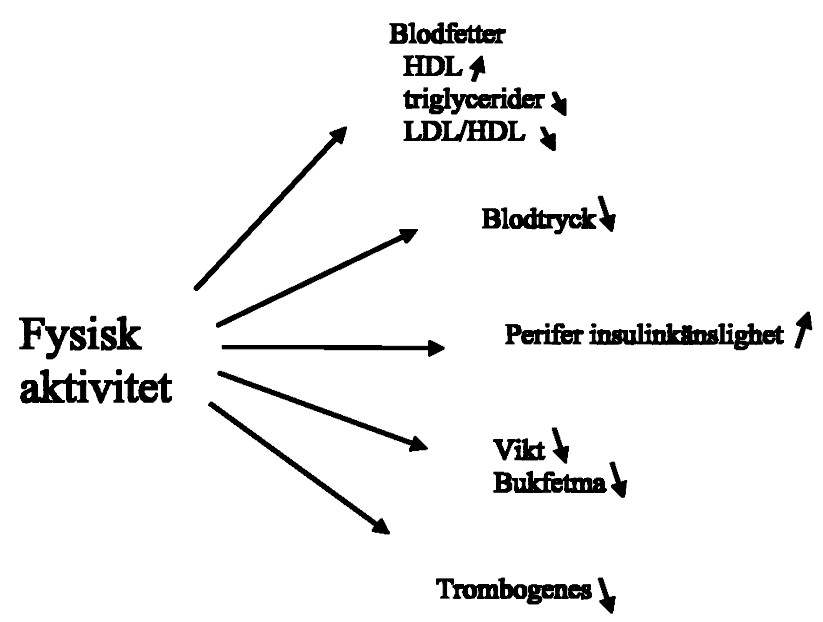

Fig. 1. Effekter av fysisk aktivitet vid metabola syndromet. 
individualiseras och omskrivas till praktiska konkreta råd. Män och kvinnor med det metabola syndromet bör betraktas som riskindivider och motionsdosen bör ökas succesivt. Vid misstanke om koronarsjukdom eller annan hjärtsjukdom bör adekvat utredning föregå motionsrådgivning. Varningssignaler bör diskuteras och resultaten av givna råd följes gärna upp vid ett återbesök. Remiss till speciellt anpassad motionsgrupp kan vara framgangsrikt och har blivit ett fungerande arbetssätt i många primärvårdsområden i Sverige (20).

\section{Sammanfattning}

Övervikt, bukfetma och det metabola syndromet ökar i Sverige. Brist på fysisk aktivitet kan spela en stor roll i genesen till det metabola syndromet. Genom den ökade energiförbrukningen är fysisk aktivitet ett sätt att förebygga och behandla övervikt och bukfetma. Fysisk aktivitet har även positiva effekter på lipoproteinomsättningen, blodtryck, perifer insulinresistens och fibrinolys. Fysisk aktivitet kan genom sina multifaktoriella verkningsmekanismer vara ett effektivt sätt att förebygga och behandla det metabola syndromet. Daglig låggradig fysisk aktivitet rekommenderas samt konditionsbefrämjande aktiviteter av mattlig intensitet i 30 min eller mer minst 2-3 ggr i veckan.

\section{References}

1. Rasmussen F, Johansson M: Increase in the prevalence of overweight and obesity from 1995 to 1998 among 18-year-old males in Sweden. Acta Paediatr 2000;89:888-9.

2. Rosengren A, Eriksson H, Larsson B et al: Secular changes in cardiovascular risk factors over 30 years in Swedish men aged 50: the study of men born in 1913, 1923, 1933 and 1943. J Intern Med 2000;247:111-8.

3. Groop L, Orho-Melander M: The dysmetabolic syndrome. J Intern Med 2001;250:105-20.

4. Grundy SM: Hypertriglyceridemia, insulin resistance and the metabolic syndrome. Am J Cardiol 1999;83:25-9.

5. Despres JP: Health consequences of visceral obesity. Ann Med 2001;33:534-41.

6. Hellénius M-L, Rosell M, de Faire U: High prevalence of overweight and metabolic syndrome among 60 year old woman and men in Stockholm, Sweden (Abstract). Atherosclerosis 2000;151:276.

7. Hellénius M-L, de Faire U, Heinonen M, Rosell M: Samband mellan fysisk aktivitet och det metabola syndromet hos 60-åriga män och kvinnor (Abstract). Svenska Läkaresällskapets handlingar. Hygiea 2000;109:136.

8. Byberg L, Zethelius B, McKeigue PM, Lithell HO: Changes in physical activity are associated with changes in metabolic cardiovascular risk factors. Diabetologia 2001;44:2134-9.
9. Eriksson J, Taimela S, Koivisto VA: Exercise and the metabolic syndrome. Diabetologia 1997;40:125-35.

10. Anderssen SA, Hjermann I, Urdal P et al: Improved carbohydrate metabolism after physical training and dietary intervention in individuals with the "atherothrombogenic syndrome". Oslo Diet and Exercise Study (ODES). A randomized trial. J Intern Med 1996; 240:203-9.

11. Hellénius M-L, de Faire U, Berglund B et al: Diet and exercise are equally effective in reducing risk for cardiovascular disease. Results of a randomized controlled study in men with slightly to moderately raised cardiovascular risk factors. Atherosclerosis 1993;103:81-91.

12. Hellenius ML, Brismar KE, Berglund BH, de Faire UH: Effects on glucose tolerance, insulin secretion, insulinlike growth factor 1 and its binding protein, IGFBP-1, in a randomized controlled diet and exercise study in healthy, middle-aged men. J Intern Med 1995;238:12130.

13. Pan XR, Li GW, Hu YH et al: Effects of diet and exercise in preventing NIDDM in people with impaired glucose tolerance. The Da Qing IGT and Diabetes Study. Diabetes Care 1997;20:537-44.

14. Tuomilehto J, Lindström J, Eriksson J et al: Prevention of type 2 diabetes mellitus by changes in lifestyle among subjects with impaired glucose tolerance. N Engl J Med 2001;344:1343-50.

15. Diabetes Prevention Program Research Group. Reduction in the incidence of type 2 diabetes with lifestyle intervention and metformin. N Engl J Med 2002;346: $393-403$.

16. NIH Consensus Development Panel on Physical Activity and Cardiovascular Health. Physical activity and cardiovascular health. JAMA 1996;276:241-6.

17. Pollock ML: The recommended quantity and quality of exercise for developing and maintaining cardiorespiratory and muscular fitness, and flexibility in healthy adults. Med Sci Sports Exerc 1998;30:975-91.

18. Pollock ML, Franklin BA, Balady GJ et al: AHA Science Advisory. Resistance exercise in individuals with and without cardiovascular disease: benefits, rationale, safety, and prescription: an advisory from the Committee on Exercise, Rehabilitation, and Prevention, Council on Clinical Cardiology, American Heart Association; Position paper endorsed by the American College of Sports Medicine. Circulation 2000;101:828-33.

19. Levine JA, Schleusner SJ, Jensen MD: Energy expenditure of nonexercise activity. Am J Clin Nutr 2000; 72:1451-4.

20. Hellénius M-L, Arborelius E: Motion på recept kan hjälpa patienten ändra sina vanor. Läkartidningen 1999;96:3343-6.

\section{Mai-Lis Hellénius}

Centrum för klinisk hjärtkärlforskning och Konung Gustaf V's Forskningsinstitut, Karolinska sjukhuset, SE-I7I76 Stockholm, Sweden. Tel: 08 51773396; Fax: 08 51775855; E-mail: mai-lis.hellenius@ks.se 